\title{
VENEZUELA: ¿LA REVOLUCIÓN PIERDE SU ENCANTO?
}

\author{
Venezuela: Is the Revolution Losing its Charm?
}

\author{
ÁNGEL E. ÁLVAREZ \\ Instituto de Estudios Politicos, Universidad Central de Venezuela
}

\begin{abstract}
RESUMEN
Se analiza el desempeño político doméstico e internacional del gobierno y se formulan pronósticos sobre decisiones gubernamentales en el corto plazo. En el año 2007, el presidente Chávez hizo un intento mayor para profundizar, consolidar y radicalizar la llamada "revolución bolivariana". Al mismo tiempo, emergieron nuevos actores políticos de oposición democrática (los estudiantes como movimiento sociopolítico) y produjeron la primera derrota electoral a Chávez en nueve años. En el campo económico, el gobierno se empeña a continuar políticas económicas intervencionistas que, paradójicamente, han producido escasez e inflación en un contexto de continuo boom petrolero. En política exterior, el gobierno ha sufrido importantes reveces y la imagen internacional del presidente se ha deteriorado. En el año 2008 se profundizarán las líneas de conflicto doméstico e internacional que se abrieron en el contexto de la campaña por el cambio constitucional. La elección de los gobiernos locales y estaduales va a ser una nueva oportunidad para la polarización política, pese a los esfuerzos hechos tanto por los moderados pro gobierno como los de oposición.
\end{abstract}

Palabras clave: Venezuela, democracia, conflicto, elecciones, polarización.

\begin{abstract}
The article analyzes domestic and international performance of the government and offers short time predictions on political conflict and the government's choices. In 2007, President Chávez made an important attempt to radicalize and consolidate the so-called "Bolivarian revolution". Altogether, new democratic opponents (namely, a new student movement) emerged and won a significant election for the first time in nine years. The government has stubbornly refused to make significant economic reforms, despite evident failures leading to scarcity and inflation, even though oil prices continue to boom. The government has suffered important failures in foreign policy and Chavez' international image has been damaged. In 2008, the main lines of conflict, both domestic and international, already exploited in the constitutional reform campaign will be deepened during the municipal and state campaigns. The new elections will provide a new opportunity for polarization, despite the efforts made by moderate sectors from both the government and opposition.
\end{abstract}

Key words: Venezuela, democracy, conflict, elections, polarization.

\section{INTRODUCCIÓN}

Este trabajo describe lo ocurrido en el 2007 en el plano político doméstico e internacional y formula algunos pronósticos de lo que será el cuadro político venezolano en el 2008. El año 2007 estuvo signado por el intento del presidente Chávez de profundizar, consolidar y radicalizar la llamada "revolución bolivariana", el surgimiento de nuevos actores políticos 
de oposición democrática (los estudiantes como movimiento sociopolítico); la continuidad de políticas económicas intervencionistas que, paradójicamente, han producido escasez e inflación en un contexto de continuo boom petrolero y, finalmente, el fracaso de iniciativas venezolanas de política exterior en Venezuela y el deterioro de la imagen del país en el contexto internacional. En el año 2008 muy probablemente se profundizarán las líneas de conflicto doméstico e internacional que se abrieron en el contexto de la campaña por el cambio constitucional impulsado por Chávez, debido a que en octubre tendrá lugar un nuevo evento de la apretada agenda de elecciones que los venezolanos han tenido que cumplir desde 1998. La elección de los gobiernos locales (alcaldías, concejos municipales y juntas parroquiales) y estaduales (gobernadores y consejos) va a ser una nueva oportunidad para que el gobierno y la oposición continúen profundizando las líneas de división sociopolítica (cleavages) que les separan, pese a los llamados al diálogo hechos por algunos sectores del gobierno y de la oposición, así como a la amnistía parcial que el gobierno dictó a finales de diciembre a favor de algunos prisioneros políticos.

\section{EL CONTEXTO POLÍTICO: DEMOCRACIA AMENAZADA}

La propuesta de cambio constitucional presentada por el presidente Hugo Chávez, ampliada por la Asamblea Nacional y rechazada por la mayoría de los venezolanos el domingo 2 de diciembre del 2007, fue presentada a los electores en dos bloques. ${ }^{1}$ El llamado Bloque A incluía la reforma de 46 artículos. La mayoría de ellos (33) fueron propuestos por el presidente. El Bloque B contenía otros 23 artículos propuestos por la Asamblea Nacional (AN). Ambos bloques fueron rechazados por la mayoría, aunque por un margen muy pequeño (ver Tabla 1). Considerando el último reporte del Consejo Nacional Electoral, emitido con base a un total de $94 \%$ de las actas de votación, las diferencias fueron 1,41 puntos porcentuales en el caso del llamado Bloque A y 2,11 en del Bloque B.

Tabla 1: Resultados del Referéndum por bloques de Artículos

\begin{tabular}{|c|c|c|c|c|}
\hline \multirow{2}{*}{ Opción } & \multicolumn{2}{|c|}{ Bloque A } & \multicolumn{2}{|c|}{ Bloque B } \\
\hline & Votos & Porcentaje & Votos & Porcentaje \\
\hline SÍ & 4.379 .392 & $49,29 \%$ & 4.335 .136 & $48,94 \%$ \\
\hline $\mathrm{NO}$ & 4.504 .354 & $50,7 \%$ & 4.522 .332 & $51,05 \%$ \\
\hline
\end{tabular}

Fuente: Elaboración del autor con base a datos del primer boletín oficial del Consejo Nacional Electoral (CNE).

La pregunta sometida a consulta popular fue. “¿Aprueba usted el proyecto de Reforma Constitucional con sus Títulos, Capítulos, Disposiciones Transitorias, Derogatoria y Final, presentado en dos bloques y sancionado por la Asamblea Nacional, con la participación del pueblo y con base en la iniciativa del presidente Hugo Chávez?". 
Los datos de la Tabla 1 corresponden al primer boletín oficial y parcial del CNE. El mismo, que fue emitido horas después de cerrado el acto de votación del día 3 de diciembre del 2007. Aunque han pasado meses desde la emisión de este boletín, aún el organismo electoral no ha publicado los resultados definitivos. La presidenta del cuerpo, Tibisay Lucena, al hacer del conocimiento público estos resultados, los calificó de preliminares y afirmó que indicaban una tendencia irreversible, pero a estas alturas nadie sabe cuál fue la diferencia real entre las opciones vencedoras y perdedoras.

En todo caso, los resultados disponibles evidencian una variación importante del apoyo popular a Chávez respecto de las elecciones presidenciales de diciembre del 2006. Los resultados de este referéndum contrastan con los de las presidenciales del 2006. Pese a las distintas características formales de estas dos elecciones, sus resultados pueden compararse porque el propio Chávez convirtió la reforma constitucional en un plebiscito sobre su mandato. Esto no es nuevo. La estrategia plebiscitaria ha sido una constante en las nueve elecciones que han tendido lugar desde 1999, de las cuales sólo el referéndum revocatorio del 2004 buscaba improbar o ratificar el mandato presidencial. No obstante, Chávez siempre se ha involucrado personalmente y ha configurado las opciones y las candidaturas en disputa en términos de un plebiscito destinado a ratificarlo a él personalmente como presidente.

La estrategia plebiscitaria dio resultado en elecciones anteriores. En la campaña del 2007, Chávez sostuvo que votar por la reforma constitucional era votar por el presidente. El eslogan de campaña fue "SI-gue con Chávez". A pocas semanas de las elecciones, para dejar claro cuáles eran los artículos que más le importaban, Chávez propuso la separación de las votaciones en bloques. ${ }^{2}$ Aun así, los dos bloques tuvieron cifras muy cercanas de rechazo.

La estrategia plebiscitaria y la lectura que ha hecho Chávez de los resultados han profundizado la división política del país en tres bloques: un sector consecuentemente leal a Chávez; un sector opositor heterogéneo compuesto por los votantes identificados con alguno de los dos grandes partidos políticos (Nuevo Tiempo, de centro izquierda o Primero Justicia, de centro derecha), seguidores de grupos radicales antigubernamentales y una enorme mayoría independiente, en su mayoría crítica de los partidos opositores y, finalmente un segmento de abstencionistas crónicos que siempre ha alcanzado al menos un tercio del total de electores registrados, pero que en 2007 subió a casi el 44\% de los votantes.

La segmentación del electorado venezolano resulta de una amalgama de divisiones sociopolíticas. La más evidente de estas divisiones es la socioeconómica. Desde el año 2000, Chávez ha sido respaldado más por los pobres y que por las clases medias, pese a que en las elecciones de 1998, las primeras ganadas por Chávez, el presidente logra apoyo en todos los sectores de la población. En estas elecciones, Chávez ganó el respaldo de las capas medias terriblemente descontentas con los partidos tradicionales debido al

2 Chávez no fue el primero que pidió la separación. Esta petición fue originalmente hecha por la oposición, pero con el fin de distinguir las propuestas de Chávez de los añadidos hechos por la $\mathrm{AN}$, sino para que se votaran separadamente las reformas sociales (ampliamente respaldadas por los votantes) de las polémicas reformas políticas. La propuesta de la oposición fue rechazada por la AN aduciendo inconstitucionalidad del procedimiento de separación, 
deterioro continuo de su nivel de ingresos y a la patente corrupción. Una vez electo, durante la luna de miel del proceso constituyente de 1999, Chávez alcanza respaldos de más del 80\% de los electores según todas las encuestas conocidas. Una vez concluido este proceso, Chávez ha explotado políticamente no sólo el enfrentamiento de clases (Dietrich 2005) y la polarización entre pobres y ricos en su lucha contra el neoliberalismo (Roberts 2003), sino también la lucha entre coaliciones sociales heterogéneas que se enfrentan por diversos temas (Álvarez Díaz 2006).

Una primera división sobre la cual se monta el liderazgo de Chávez es el tema petrolero. El manejo de los recursos petroleros del Estado divide a los venezolanos en dos grupos: uno, liderado por Chávez, sostiene una concepción rentista de la política, muy parecida a la que en el pasado (antes de los ajustes neoliberales de los años noventa) sostenían AD y COPEI. Esta concepción económica rentista aspira a sostener la economía principalmente con base a los recursos obtenidos en el sector externo, exportador de petróleo y derivados, y mantener subsidios al sector privado de la economía (que incluyen como los más emblemáticos, pero no se limitan al precio de la gasolina, el precio del dólar mediante la sobrevaluación de bolívar, y el otorgamiento de licencias de importación de bienes de consumo). Mediante esta política rentista se financia y se sostiene una amplia coalición de clases que incluye no sólo a los más pobres, incorporados mediante políticas sociales distributivas, sino también sectores importadores, comerciantes, la banca y de clase media en general que se benefician principalmente por medio del subsidio al dólar y el acceso a bienes de consumo importados a bajo costo. Frente a este sector, están los exportadores, productores agrícolas y agroindustriales, industriales en general y trabajadores formales del sector industrial que, por razones obvias, se perjudican de las restricciones a la exportación y del incentivo para la importación. A estos se suman aquellos sectores tecnocráticos de la administración pública en general y de la industria petrolera en particular que aspiran a la autonomía de PDVSA y a reducir el impacto de los shocks petroleros en el recto de la economía. Este sector fue el que condujo el paro petrolero del 2002-2003 que llevó finalmente al despido de cerca de 20 mil de los 30 mil trabajadores de distinto nivel que estaban en la nómina de PDVSA.

El gobierno ha impuesto controles de precios y de cambio, promovido la invasión de propiedades rurales $\mathrm{y}$, desde la perspectiva de los empresarios, no ha garantizado la seguridad jurídica de los inversionistas. Pero al tiempo que golpea a la burguesía industrial y agroindustrial, genera oportunidades de negocios para importadores que obtienen licencias para llevar a Venezuela bienes y servicios con dólares extremadamente baratos. La diferencia entre el tipo de cambio oficial y el real es como de 300\%. Del subsidio cambiario, así como de las colocaciones de papeles del gobierno a tasas generosas, se ha beneficiado también la banca privada.

La coalición populista a favor de Chávez está integrada principalmente por la así llamada "boli-burguesía" de importadores, proveedores del sector público, contratistas de obras públicas, comerciantes y banqueros, cuya organización gremial más emblemática es EMPREVEN (Empresarios por Venezuela), creada recientemente, así como FEDEINDUSTRIAS (Federación de Cámaras y Asociaciones de Artesanos, Micros, Pequeñas y Medianas 
Industrias y Empresas) la organización que tradicionalmente ha agrupado a los pequeños y medianos industriales, algunos trabajadores formales más las grandes masas de trabajadores informales canalizadas y subsidiadas por el gobierno a través de redes clientelares creadas bajo el manto de las llamadas "misiones" sociales.

Contra Chávez se ha erguido tradicionalmente una coalición de industriales, productores agrícolas y exportadores, pero también el grueso de los trabajadores formales, incluso aquellos que laboran en el sector público, así como la mayoría de los sectores progresistas de las universidades nacionales y los intelectuales. Más recientemente, como consecuencia de la incapacidad del gobierno para resolver problemas endémicos de servicios de salud, educación y vivienda, más la agudización de los problemas de criminalidad, inflación y escasez de alimentos, medicamentos y otros bienes esenciales, más las tendencias autocráticas del presidente han empujado hacia la oposición a algunos sectores tradicionalmente pro gubernamentales.

Otras dos líneas de división importante es la que separa a los trabajadores formales de los informales. Chávez no ha logrado capitalizar el apoyo mayoritario de los trabajadores de la economía formal, ni siquiera en el sector público. Aunque intentó desmontar la tradicional CTV y creó la Unión Nacional de Trabajadores (UNETE), aún es apoyado mucho más por los informales que por los formales. Los trabajadores informales del sector comercio y de servicios, principalmente vendedores ambulantes y localizados en mercados de baratijas, han sido expresamente protegidos por la legislación y las políticas del Estado en detrimento del nivel real de ingreso de aquellos que trabajan en el comercio y los servicios del sector formal. No obstante, al menos en Caracas, la capital del país, un grupo importante de estos trabajadores informales han sido desalojados de sus puestos de trabajo en las calles por el alcalde pro gubernamental, Freddy Bernal.

Otra línea de división presente en el discurso de Chávez es racial. Pese a que la población venezolana, a todos los niveles socioeconómicos, es mestiza y la población indígena representa apenas cerca del $2 \%$ del total, Chávez ha intentado explotar la división entre indígenas y el resto de la población y, más recientemente, entre los así llamados "afrodescendientes" y los "blancos oligarcas". La división tiene poco soporte en la estructura real de la población, pero políticamente ha dado algunos dividendos en virtud de que el propio Chávez es más oscuro de piel que el promedio de los venezolanos y, principalmente, que el promedio de los presidentes electos desde 1958.

Finalmente, las cifras de la elección discriminadas por estados sugieren una línea de división inexistente previamente. Durante la mayor parte de la llamada "cuarta república", y también en las múltiples elecciones realizadas durante la era de Chávez, los partidos habían tendido a obtener una votación uniforme en todo el país. En otras palabras, no se habían producido importantes divisiones regionales en el país. Las cifras por distritos electorales en Caracas (o parroquias, en la división política administrativa de Venezuela), así como otras en las grandes ciudades, hacen pensar que los apoyos a Chávez no se distribuyen uniformemente.

De los cinco municipios en los que está dividida la ciudad, tres están gobernados por la oposición y dos por alcaldes del partido de Chávez (antes MVR y ahora PSUV). Los municipios con alcaldes opositores están poblados principalmente, pero no exclusivamente, 
por sectores de clase media alta y clase alta. Por el contrario, los municipios gobernados por el PSUV son predominantemente, aunque de nuevo no exclusivamente, de clase media baja y baja. En las elecciones de alcaldes del 2004, la ciudad terminó polarizada política y socialmente. En el referéndum del 2007 las cosas cambiaron.

La oposición ha seguido predominando ampliamente en los municipios y parroquias de clase media alta y alta, pero la reforma fue rechazada en todos los municipios de la ciudad, incluyendo muchas parroquias de clase baja de los municipios dominados tradicionalmente por partidarios del gobierno de Chávez. En el Municipio Libertador, por ejemplo (cede del Poder Nacional y gobernado por el Alcalde Freddy Bernal, ex miembro de la Policía Metropolitana que se unió a la rebelión militar de 1992 y que ha sido un fiel seguidor del presidente) la reforma pierde no sólo en las parroquias de clase media donde Chávez perdió en el 2006 (San Bernardino, La Candelaria, San Pedro y El Recreo) sino también en diez parroquias predominantemente de clase baja (de un total de 16 parroquias pobres) y en una de clase media donde antes había ganado (El Paraíso). También pierde en el Municipio Sucre, gobernada por el PSUV, debido al cambio ocurrido en la parroquia Petare, habitada predominantemente por votantes de clase baja y media baja.

En el referéndum del 2007, se observa una diferencia importante entre las entidades federales. Los estados más poblados tendieron a rechazar la reforma, en contraste con los menos poblados. El porcentaje de población de las entidades federales en Venezuela es un buen proxy del nivel de urbanización e industrialización. Las tres ciudades más grandes están en las entidades federales más pobladas. Caracas abarca el Distrito Capital y parte del estado Miranda; Maracaibo es capital del Zulia, y Valencia lo es de Carabobo. En los estados más grandes también se asientan los más importantes parques industriales.

La reforma propuesta por Chávez y la AN fue rechazada en la mayoría de los estados densamente poblados, más industrializados y más urbanizados (ver Gráficos 1 y 2). El Bloque A de la reforma fue rechazado en las cuatro entidades federales con población superior al 7\% del total de los habitantes del país (Zulia, Miranda, Carabobo y Distrito Capital). En estas cuatro regiones, los votantes en contra de la reforma excedieron a los que la apoyaron en cifras que van desde los 5 a los 14 puntos porcentuales, cifras muy por encima de los márgenes observados a nivel nacional. De los ocho estados de tamaño mediano (con porcentajes de población entre 3\% y 6\%) la reforma fue rechazada en cuatro (Anzoátegui, Lara, Mérida y Táchira). Por el contrario, la reforma fue respaldada en todos los estados pequeños salvo en uno (Nueva Esparta). Otro dato importante es que la reforma pierde en los dos estados gobernados por la oposición (Zulia y Nueva Esparta). Los otros siete estados en los que pierde Chávez son gobernados por miembros de su partido, tres de ellos militares retirados (Táchira, Miranda y Carabobo). Con el Bloque B de los artículos de la reforma sucedió lo mismo, salvo que se añade Falcón a la lista de los estados medianos en los que perdió Chávez. En pocas palabras, existe una correlación alta, inversa y estadísticamente significativa entre el tamaño de la población de las entidades federales y el apoyo al llamado "socialismo del siglo XXI" que la reforma habría constitucionalizado ${ }^{3}$. 
Gráfico 1: Distribución por estados del voto por la reforma (Bloque A) según porcentaje de habitantes.

Porcentaje del voto a favor de la reforma (Bloque A)

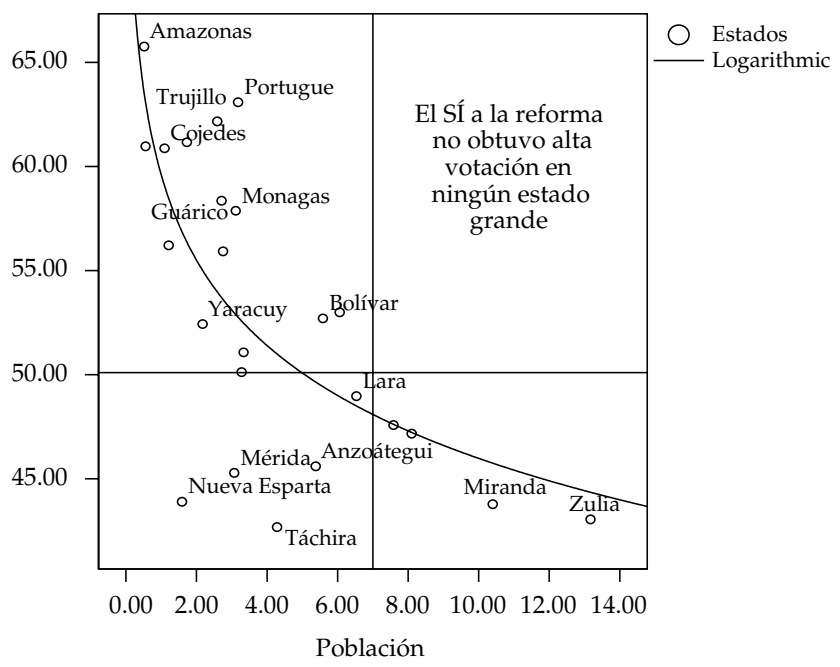

Fuente: elaboración propia con base a datos del Consejo Nacional Electoral e Instituto Nacional de Estadísticas.

Gráfico 2: Distribución por estados del voto por la reforma (Bloque B) según porcentaje de habitantes.

Porcentaje del voto a favor de la reforma (Bloque B)

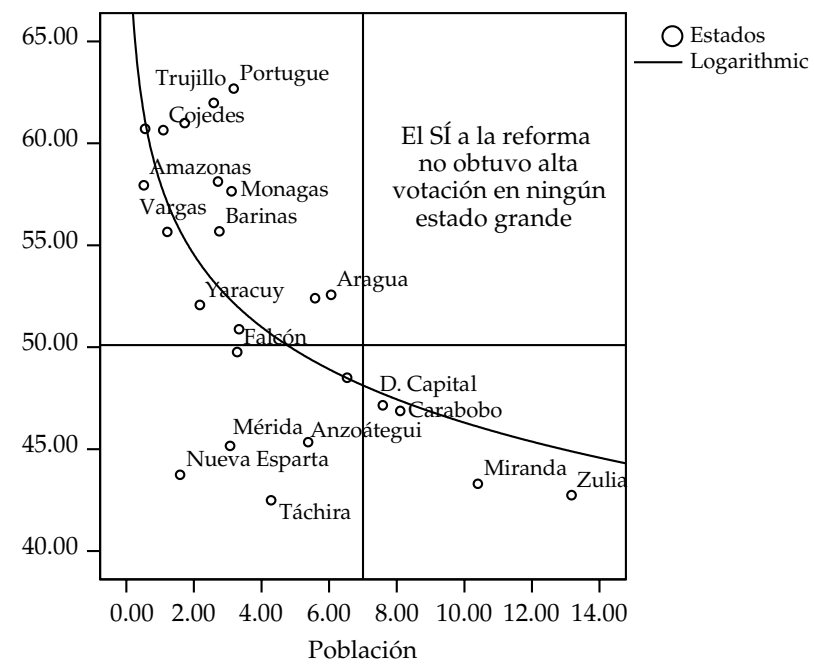

Fuente: elaboración propia con base a datos del Consejo Nacional Electoral e Instituto Nacional de Estadísticas. 
Los resultados del referéndum a nivel de los estados también contrastan con los de las presidenciales del 2006. En las presidenciales, Chávez no sólo fue reelecto sino que ganó en todos los estados del país. Por el contrario, en el pasado referéndum el Bloque A fue rechazado en 9 de 24 de las entidades federales y el B en 10 de ellas. Además, en las regiones donde la mayoría de los votantes respaldó a la reforma, la votación recibida por estas fue menor a la obtenida por Chávez en las presidenciales.

En el Gráfico 3 se observa que la diferencia entre los dos primeros candidatos presidenciales en las elecciones del 2006 (Hugo Chávez y el opositor y gobernador del estado Zulia, Manuel Rosales) fue: a) generalizada (es decir, favorable a Chávez en todas las entidades federales); y b) amplia (por encima de los 10 puntos porcentuales en todos los estados, menos tres: Mérida, Táchira y Zulia). En todos los estados la diferencia entre los votos de Chávez y los de Rosales en el 2006 fue bastante mayor a la existente entre los votos presidenciales de Chávez y las del "NO" a ambos bloques de la reforma. En tres estados (Mérida, Táchira y Zulia) esta diferencia es negativa; es decir, en estos tres estados, los votos por el "NO" fueron superiores a los obtenidos por Chávez un año antes.

En el Gráfico 4, que presenta las diferencias entre Chávez y Rosales en el 2006 comparadas con las dos opciones del referéndum ("NO" versus "SI'") en cada bloque de artículos, se ve cómo la amplia ventaja del presidente en el 2006 en casi todas las regiones se acorta en el 20006. En la mayor parte de los estados donde la reforma pierde, Chávez había ganado por

Gráfico 3: Diferencia porcentual entre la votación de H. Chávez y M. Rosales en el 2006 y entre la votación de Chávez en el 2006 y los votos contra la reforma en el 2007

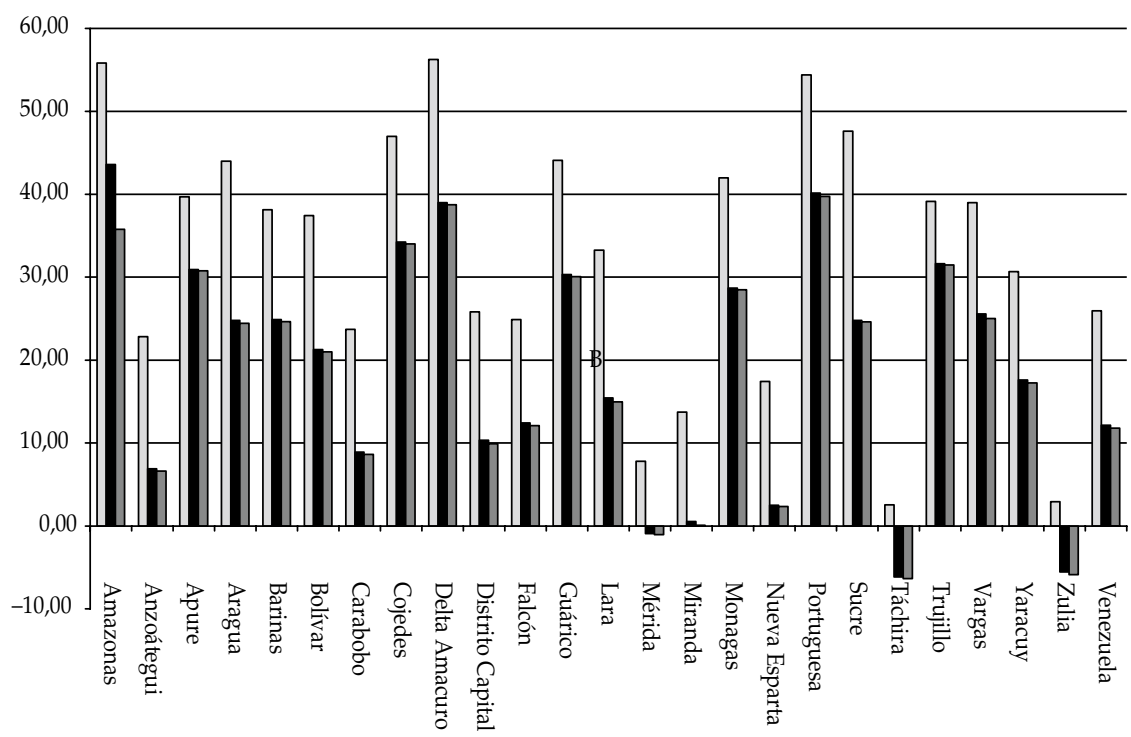

$\square$ Chávez vs. Rosales $2006 \square$ Chávez vs. No (Bloque A) $\square$ Chávez vs. No (Bloque B)

Fuente: elaboración propia con base a datos del Consejo Nacional Electoral. 
Gráfico 4: Diferencia porcentual entre la votación de H. Chávez y M. Rosales en el 2006 y entre las dos opciones del referéndum 2007

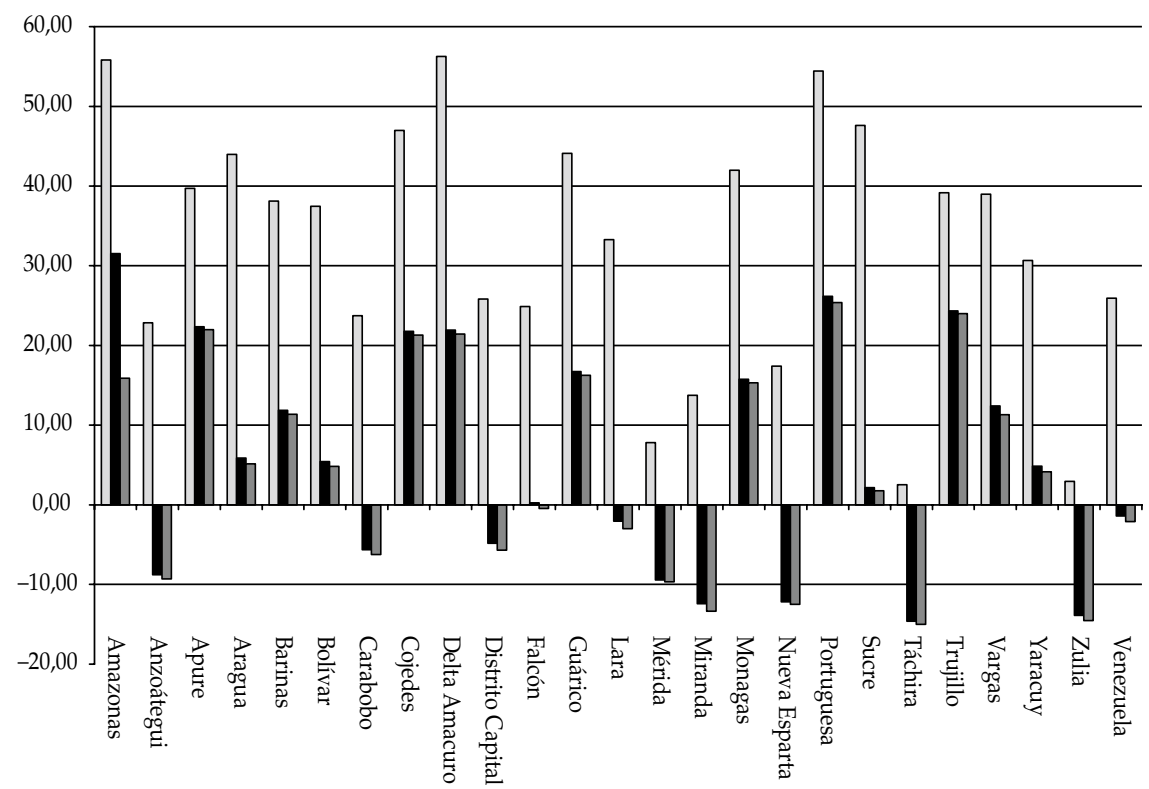

$\square$ Chávez vs. Rosales $2006 \square$ Chávez vs. No (Bloque A) $\square$ Chávez vs. No (Bloque B)

Fuente: elaboración propia con base a datos del Consejo Nacional Electoral.

amplio margen. Por ejemplo, en Aragua, Carabobo, Distrito Capital y Lara, Chávez le ganó a Rosales por más de 20 puntos. En diciembre del 2007, la reforma no sólo es rechazada en esos estados, sino que en algunos casos (como en Anzoátegui, Carabobo y Distrito Capital) la diferencia entre el rechazo y el apoyo a la reforma fue por un margen superior al registrado a nivel nacional y cercano a los 5 puntos. En los pocos estados donde Chávez ganó por poco margen en el 2006 (Mérida, Táchira y Zulia), el rechazo a la reforma fue aún mucho más marcado, alcanzado márgenes cercanos o mayores a los 10 puntos.

Pero la ventaja de Chávez se acortó no sólo en los estados donde la reforma fue rechazada, sino también en los que ésta ganó el referéndum. Por ejemplo, en el estado Amazonas, Chávez ganó por una diferencia de más de 55 puntos en el 2006, mientas los bloques del referéndum fueron aprobados por márgenes cercanos a 30 y 15 puntos respectivamente. En Delta Amacuro, Chávez ganó por una amplísima ventaja de casi 59 puntos, pero la reforma ganó con márgenes apenas superiores a los 20 puntos. En Falcón, donde en la práctica ocurrió un "empate" entre las dos opciones del referéndum, Chávez había ganado con una ventaja cercana a 25 puntos, pero el bloque A de la reforma ganó por un margen cercano a 1 punto y el bloque B fue rechazado con un margen similar. Algo parecido puede verse en estados emblemáticamente "chavistas" como Guárico, Vargas, Monagas y Portuguesa. En todos estos estados, el gobierno regional y la mayoría de los gobiernos locales están controlados por el PSUV o sus aliados. En los estados Aragua y Sucre, gobernados por PODEMOS 
(partido que apoyó a Chávez en el 2006, pero que se sumó al bloque de organizaciones que rechazaron la reforma constitucional en el 2007) Chávez repitió el triunfo, pero con márgenes muy reducidos. En Aragua, Chávez fue reelecto por poco menos de 45 puntos de ventaja por encima de Rosales, pero los dos bloques de la reforma obtuvieron ventajas pequeñas (alrededor de los 5 puntos). En Sucre este fenómeno es aún más marcado. Allí Chávez ganó por un margen cercano a los 48 puntos, pero los votos por la reforma excedieron a los contrarios por apenas 2 puntos. En suma, las elecciones han dejado un país menos políticamente uniforme, en el que Chávez ya no tiene un claro control de la mayoría que lo eligió en el 2006.

\section{Pese a la derrota, Chávez mantiene su postura ideológica radical}

La confrontación política no sólo es más pronunciada sino más explícitamente ideológica. Mientras hasta el 2006 la confrontación había sido esencialmente en términos de respaldo y rechazo a Chávez y su gestión y estilo personalista y autoritario, en esta oportunidad la contienda sumó al componente plebiscitario la clara identificación de Chávez con un modelo económico socialista, un cambio profundo en la estructura del Estado y una transformación radical de las formas de propiedad.

Al reconocer su derrota, Chávez calificó de pírrica la ventaja de la oposición. Dos días después, usaba palabras aún más duras y hasta obscenas para calificar el triunfo opositor. Pero lo más importante es que reiteradamente ha dicho que no retira ni una letra de su propuesta. Chávez interpreta los resultados como un triunfo moral, opina que el pueblo "no estaba preparado" todavía y afirma que la reforma fue rechazada "por ahora" (repitiendo la frase que acuñó el 4 de febrero de 1994 cuando reconoció el fracaso de su intento golpista) ${ }^{4}$. Ha acusado de traición a los votantes que le apoyaron en el 2006 pero que se abstuvieron o votaron en contra de la reforma en el 2007. Reclama a sus seguidores el faltante de tres millones de votos a su favor. Más aún, dice que su derrota ha sido la victoria del imperialismo. En fin, al leer su derrota como una "casi victoria" contra enemigos externos y sus "lacayos" internos, Chávez radicaliza su discurso y deja poco margen para que tengan éxito los llamados a la reconciliación, hechos por los moderados de ambos lados desde el instante mismo en el que los resultados electorales fueron anunciados.

Los cambios que Chávez se empeña en imponer por cualquier vía contemplan cambios esenciales a la estructura del Estado y las formas de propiedad. De todos ellos, los más importantes afectan la distribución de poder entre el gobierno central y las autoridades electas a nivel local y regional; el derecho de propiedad; el papel del Estado en la economía; las atribuciones del presidente y, muy destacadamente, la duración del mandato presidencial (pasando de seis años a siete) y las oportunidades de reelección (que pasarían de una sola reelección a la reelección indefinida).

Para el logro de estos cambios Chávez propuso inicialmente el cambio de poco más de una treintena de artículos de la Constitución de 1999. Su propuesta fue introducida a la

4 La frase "Por ahora...", ha inundado las principales ciudades del país escrita en rojo intenso sobre el fondo blanco de enormes carteles publicitarios. 
AN el día 15 de agosto del 2007. En un tiempo récord (el 2 de noviembre) la AN ya había aprobado la propuesta presidencial, añadido la reforma de 36 artículos más, incorporado veinticinco disposiciones transitorias y redactado una larga exposición de motivos que perfilaba la transición al socialismo.

Los cambios propuestos, rechazados por el pueblo pero mantenidos por Chávez desde la noche misma en la que reconoció la "pírrica" victoria opositora, son tantos y tan variados que no hay manera de presentarlos todos detalladamente en un trabajo de estas dimensiones. La profundidad de los cambios es tal que el propio presidente Chávez los ha llamado "una revolución dentro de la revolución".

El contenido del cambio constitucional era tan profundo que obviamente excedía los supuestos de la reforma constitucional, tal como este es definido en el texto de la Constitución vigente. Algunos partidos y personalidades de izquierda que hasta hace muy poco tiempo se consideraban seguidores consecuentes del presidente (tales como el partido Por la Democracia Social, PODEMOS, y el ex ministro de Defensa y artífice de la derrota militar del golpe del 2002, General en Jefe Raúl Isaías Baduel) se opusieron a la reforma argumentado que, con base al texto constitucional vigente, cualquier cambio que altere sustancialmente la estructura del Estado sólo podía ser realizado por medio de una ANC. Según esta opinión, la propuesta de Chávez ni era una reforma (pues afectaba la esencia misma del orden constitucional) ni era constitucional (pues el procedimiento adoptado no permitía realizar tales cambios). Tal argumento fue rechazado en sentencias reiteradas del Tribunal Supremo de Justicia (TSJ) que, dicho sea de paso, ha estado ampliamente dominado por magistrados afines al presidente Chávez. Para muestra un botón: la presidenta del TSJ, Luisa Estela de Morales, formó parte de la comisión que redactó la propuesta presentada por el presidente. No obstante, incluso algunos magistrados emblemáticamente pro gubernamentales salvaron sus votos en varias decisiones en contra de los demandantes de nulidad de los actos del gobierno en esta materia y los solicitantes de amparos por violación de derechos constitucionales por parte del gobierno.

La profundidad y amplitud de la propuesta de cambio político es tan grande, que en este trabajo se hace imposible presentarla y discutirla detalladamente. Por ello, la propuesta va a ser resumida en cuatro áreas fundamentales: el modelo democracia y el llamado "empoderamiento" del pueblo o "poder popular"; el poder presidencial; el sistema de derechos y garantías ciudadanas; el sistema económico. Se sigue el texto de la propuesta de cambio constitucional pues, como se ha dicho, pese a haber sido rechazada por los votantes, el presidente y sus seguidores en la $\mathrm{AN}$ insisten en mantenerla y materializarla por otros medios.

La Constitución de 1999 evitó el uso del término "democracia representativa" y eliminó toda mención a los partidos políticos. No obstante, esta Constitución creó un sistema político democrático pluralista, multipartidista (al menos hasta las elecciones legislativas del 2005) basado en el voto popular como instrumento fundamental para constituir y elegir los poderes públicos. Cierto es que la Constitución define otras formas de participación distinta al voto, pero no es menos cierto que, como en toda democracia contemporánea, los 
órganos del poder público (las cinco ramas en que éste queda divido en esta Constitución) ${ }^{5}$ surgen directa o indirectamente del voto popular. Hugo Chávez y los defensores de su propuesta de cambio dicen buscar una profundización de la democracia, una democracia socialista del "siglo XXI".

Para ello, en primer lugar, Chávez persigue crear un nuevo poder, el llamado "poder popular" como órgano del Estado y no sometido a elecciones; en segundo lugar, busca implantar una "nueva geometría" del poder o, dicho de otro modo, Chávez desea cambiar la división política administrativa aduciendo una mayor transferencia de poder a los órganos del llamado "poder popular" y en detrimento del poder y de los recursos que actualmente poseen los gobernadores y alcaldes electos popularmente. Para él, la descentralización es una de las armas usadas por el neoliberalismo para quitarle poder al Estado nacional. En el texto de la reforma rechazada, se creaban nuevas atribuciones para el presidente que, en la práctica, suprimían lo poco que queda de descentralización a nivel federal y municipal en Venezuela.

El rechazo de la propuesta de cambio constitucional no alteró la implantación del llamado "poder popular" y de la estrategia de centralización del poder. Tal estructura no estará, por ahora, en la Constitución, pero la AN ya aprobó la ley de los concejos comunales que adelantará en buena medida lo que la propuesta de cambio constitucional pretendía. La transferencia de recursos y atribuciones a nivel de las bases organizadas y las comunidades locales podría considerase, en teoría, una idea avanzada y democratizadora. El problema surge cuando los órganos del poder popular son "constituidos" (no electos) en asambleas populares (no en elecciones competitivas en las que se garantice el secreto del voto y se minimicen los riesgos de la coerción política). En tales asambleas, obviamente, que quienes estén mejor organizados, dispongan de más tiempo libre y gocen de más recursos pueden tener mucha más influencia. Además, en el clima de intensa polarización política que vive Venezuela, tales asambleas pueden convertirse en un mecanismo de exclusión de las minorías e incluso de segregación política de mayorías locales. La experiencia de discusión de la propuesta de cambio llevada a cabo mediante lo que la Asamblea Nacional llama "parlamentarismo de calle", mostró cómo los voceros de la disidencia fueron silenciados o, la mayor parte de las veces, directamente desalojados a la fuerza de las reuniones o, cuando no, se les impidió el acceso a los lugares de reunión.

Además, los miembros de estos consejos comunales creados por ley no son remunerados. En consecuencia, los partidos con capacidad de financiar activistas profesionales tendrán mucho más oportunidades de controlar los cargos no electos de voceros del poder popular. En concreto, sólo el partido de gobierno y la facción de este partido que tenga más acceso a recursos del Estado podrán financiar grandes maquinarias de voceros basadas en el patronazgo y el clientelismo. Finalmente los consejos, comunas y otros órganos de poder

La Constitución de 1999 añade el llamado "poder electoral" (formado por el Consejo Nacional Electoral y la Sala Electoral del Tribunal Supremo de Justicia) y el "poder ciudadano" (integrado por la Fiscalía General, Contraloría General y la Defensoría del Pueblo) a la tradicional división tripartita del poder público. 
popular deben ser reconocidos por el Ejecutivo para legitimar su actuación. Es poco probable que los consejos no controlados por partidarios del gobierno logren el mismo reconocimiento que los creados por los activistas del partido de gobierno.

Por último, en la práctica, Chávez está despojando de poder a los gobernadores y alcaldes. Un caso emblemático ha sido la transferencia al poder central de la Policía Metropolitana, que históricamente ha estado controlada por las autoridades locales de la capital. Asimismo, ha anunciado que procederá a tomar el control de hospitales y escuelas municipales y estadales, especialmente en aquellos estados y municipios donde la oposición tiene más oportunidades de ganar las elecciones.

La Presidencia de la República de Venezuela ha sido siempre la institución política más poderosa del país. No sólo ha tradicionalmente acumulado enormes atribuciones y facultades constitucionales y legales (Álvarez, Fernández et al. 1999), sino principalmente por razones fácticas tales como el poder real que los presidentes han tenido sobre sus partidos (Mainwaring and Shugart 1997) y, en consecuencia, en el Legislativo; por la capacidad real de influir en las postulaciones de gobernadores y alcaldes en un país débilmente federalizado y, mucho más aún, por el enorme peso que el Ejecutivo tiene en la asignación a las regiones de los recursos provenientes de la casi siempre obesa renta petrolera.

Todo lo que tradicionalmente ha sido cierto respecto del inmenso poder del Presidente de la República de Venezuela, con Chávez ha sido doblemente cierto. La Constitución de 1999 prolongó el mandato hasta seis años y ha permitido la reelección sucesiva del presidente por otros seis años más. La Constitución previa, la de 1961, establecía el mandato quinquenal y prohibía la reelección inmediata. En la práctica, Chávez ha sido el gran elector de todos los cargos influyendo no sólo en las postulaciones de candidatos a miembros de la ANC, alcaldías, gobernaciones y Asamblea Nacional, sino convirtiendo toda elección en un plebiscito sobre su persona. Incluso los dos referendos sobre la Constitución (el de 1999 y el de diciembre 2 del 2007) se han centrado en su figura. Aprobar la Constitución o no se traduce, en la campaña gubernamental, en respaldar o no al presidente. Es cierto que los presidentes de la llamada "cuarta república" influían sobre las postulaciones, pero los aparatos partidistas, más fuertemente institucionalizados que los actuales partidos de gobierno, les imponían a los presidentes más límites y forzaban arduas negociaciones entre el Ejecutivo nacional y los líderes partidistas regionales.

La propuesta de cambio constitucional defendida por Chávez habría dado aún más atribuciones formales al presidente. Aunque la reforma fue rechazada por el pueblo, algunas de las atribuciones de la presidencia han asumido de facto o con base a disposiciones legales. Las atribuciones que ya tiene el presidente de Venezuela y aquellas a las que estaban contenidas en las reforma constitucional y las que aspira aún imponer bien por vía de decretos-leyes o nuevas iniciativas de cambio constitucional son resumidas en la Tabla 2. 
Tabla 2: Comparación entre los Poderes Presidenciales previstos en la Constitución de 1999 y los introducidos en la Propuesta de Reforma

\begin{tabular}{|c|c|c|}
\hline Materia & Constitución de 1999 & $\begin{array}{c}\text { Propuesta de Reforma } \\
\text { del } 2007\end{array}$ \\
\hline Iniciativa constitucional & $\begin{array}{l}\text { Cumplir y hacer cumplir la } \\
\text { Constitución. } \\
\text { Convocar a la ANC. } \\
\text { Convocar referendos consultivos } \\
\text { materias de interés nacional, } \\
\text { así como tratados, convenios } \\
\text { o acuerdos internacionales. } \\
\text { Convocar referendos abrogatorios } \\
\text { de leyes. }\end{array}$ & Sin cambio. \\
\hline Mandato & $\begin{array}{l}\text { La duración del mandato presidencial } \\
\text { es de } 6 \text { años y podrá ser reelegido } \\
\text { una vez más. }\end{array}$ & $\begin{array}{l}\text { La duración del mandato presidencial } \\
\text { es de } 7 \text { años y podrá ser reelegido } \\
\text { indefinidamente. }\end{array}$ \\
\hline Política Exterior & $\begin{array}{l}\text { Dirigir las relaciones exteriores } \\
\text { y la política internacional de la } \\
\text { República, así como celebrar y } \\
\text { ratificar los tratados, convenios o } \\
\text { acuerdos internacionales. }\end{array}$ & No cambia. \\
\hline Fuerzas Armadas & $\begin{array}{l}\text { Comandar las Fuerzas Armadas y } \\
\text { promover y nombrar en sus cargos } \\
\text { a los altos rangos militares (a partir } \\
\text { del grado de coronel o capitán de } \\
\text { navío). }\end{array}$ & $\begin{array}{l}\text { Promover a los y las oficiales de la } \\
\text { Fuerza Armada Bolivariana en todos } \\
\text { los grados y jerarquías y designarlos o } \\
\text { designarlas para los cargos y funciones } \\
\text { correspondientes. }\end{array}$ \\
\hline Estados de excepción & $\begin{array}{l}\text { Restringir o suspender temporalmente } \\
\text { las garantías consagradas en esta } \\
\text { Constitución, salvo las referidas a: } \\
\text { derecho a la vida, prohibición de } \\
\text { tortura, incomunicación, desaparición } \\
\text { forzosa, derecho al debido proceso, } \\
\text { derecho a la información y demás } \\
\text { derechos humanos intangibles. } \\
\text { Los estados de excepción se limitan a } 30 \\
\text { días (alarma por desastres naturales), } \\
60 \text { días (emergencia económica) y } 90 \\
\text { días (conmoción interior o exterior). }\end{array}$ & $\begin{array}{l}\text { Restringir o suspender garantías } \\
\text { incluyendo el derecho al debido } \\
\text { proceso y la información, sin límite } \\
\text { de tiempo. }\end{array}$ \\
\hline
\end{tabular}




\begin{tabular}{|c|c|c|}
\hline Materia & Constitución de 1999 & $\begin{array}{c}\text { Propuesta de Reforma } \\
\text { del } 2007\end{array}$ \\
\hline Ordenación territorial & No prevista. & $\begin{array}{l}\text { Ordenar el territorio y crear el } \\
\text { régimen territorial del Distrito } \\
\text { Federal, los estados, los municipios, } \\
\text { dependencias federales y demás } \\
\text { entidades regionales, de acuerdo con } \\
\text { la ley nacional. Crear o suprimir por } \\
\text { decreto provincias federales, territorios } \\
\text { federales, ciudades federales, distritos } \\
\text { funcionales, municipios federales, } \\
\text { regiones marítimas, distritos insulares } \\
\text { y regiones estratégicas de defensa en } \\
\text { cualquier parte del territorio. (a) Crear } \\
\text { ciudades comunales y, eventualmente, } \\
\text { incentivar el desplazamiento de } \\
\text { habitantes a fin de poblarlas. } \\
\text { Nombrar y remover las autoridades } \\
\text { en tales territorios, provincias y } \\
\text { ciudades (que pueden tener el rango } \\
\text { de Vicepresidente o Ministros). } \\
\text { Decretar autoridades especiales en } \\
\text { situaciones de contingencia, desastres } \\
\text { o cualquier otra que requiera la } \\
\text { intervención inmediata y estratégica } \\
\text { del Estado, con rago superior a las } \\
\text { autoridades electas. }\end{array}$ \\
\hline Legislación & $\begin{array}{l}\text { Dictar decretos con rango de ley previa } \\
\text { autorización de la AN, convocar a } \\
\text { sesiones extraordinarias de la AN } \\
\text { y reglamentar las leyes. Disolver la } \\
\text { Asamblea Nacional en caso de que } \\
\text { ésta imponga tres votos de censura } \\
\text { al vicepresidente. }\end{array}$ & Sin cambio. \\
\hline Financiera & $\begin{array}{l}\text { Administrar la Hacienda Pública, } \\
\text { celebrar contratos, decretar gastos } \\
\text { adicionales no presupuestados previa } \\
\text { autorización de la AN, negociar la } \\
\text { deuda interna. }\end{array}$ & $\begin{array}{l}\text { Además de administrar la Hacienda } \\
\text { Pública Nacional, contratar, modificar el } \\
\text { presupuesto y negociar endeudamiento } \\
\text { interno, administra las reservas } \\
\text { internacionales, establece y regula la } \\
\text { política monetaria. }\end{array}$ \\
\hline
\end{tabular}




\begin{tabular}{|c|c|c|}
\hline Materia & Constitución de 1999 & $\begin{array}{c}\text { Propuesta de Reforma } \\
\text { del } 2007\end{array}$ \\
\hline Administración Pública & $\begin{array}{l}\text { Designar y remover al Vicepresidente } \\
\text { Ejecutivo y Ministros. Fijar el número, } \\
\text { organización y competencia de los } \\
\text { ministerios y demás órganos de la } \\
\text { Administración Pública. } \\
\text { La Administración Pública es una } \\
\text { y queda sometida a la ley y al } \\
\text { derecho. }\end{array}$ & $\begin{array}{l}\text { Nombrar y remover tantos Ministros y } \\
\text { Vicepresidentes como crea conveniente, } \\
\text { pudiendo designar a una misma } \\
\text { persona para ejercer más de un } \\
\text { cargo. } \\
\text { Se crean dos Administraciones } \\
\text { Públicas: la burocrática, sometida a } \\
\text { ley, y las misiones regidas por sistemas } \\
\text { excepcionales y experimentales } \\
\text { establecidos por decretos del } \\
\text { Ejecutivo. } \\
\text { Designar a diputados a la AN para } \\
\text { ocupar cargos públicos sin perder su } \\
\text { investidura. }\end{array}$ \\
\hline
\end{tabular}

(a) Esta figura está prevista en la normativa sobre defensa. Actualmente existen en Venezuela "teatros de operaciones" militares, principalmente en la frontera con Colombia, y zonas estratégicas militarizadas, en especial en las cercanías de las sedes de los poderes públicos y las instalaciones militares, en las cuales está prohibido por ejemplo, realizar manifestaciones públicas contrarias al gobierno.

Fuente: Elaboración propia.

Como se ha dicho, la mayor parte de las reformas propuestas, salvo la reelección indefinida y extensión de la duración del mandato a siete años, pueden ser intentadas por vía legislativa (en una AN en la que sólo 3 de 163 diputados disienten de las aspiraciones del presidente Chávez). De aprobarse esta reforma, bien sea por la vía legislativa o por nuevas iniciativas constitucionales ya anunciadas por el presidente y sus seguidores, la Presidencia resultante sería extremadamente fuerte. A sus atribuciones formales habría que sumar a la capacidad del presidente Chávez para disciplinar a los seguidores en el Congreso, más sus facultades para asignar discrecionalmente los recursos provenientes de la renta petrolera entre los gobernantes locales, regionales y directamente desde la Presidencia (principalmente a través de los programas sociales llamados "misiones"), debido a modificaciones en los estatutos de la industria petrolera, de la ley del Banco Central y otras de las leyes financieras. Un simple ejemplo del poder del Ejecutivo es el hecho de que el presidente de PDVSA es al mismo tiempo el ministro de Energía y la empresa está ahora obligada a financiar directamente varios de los programas sociales del gobierno.

José Vicente Rangel, quien ha sido un hombre clave de Chávez (ocupando cargos como ministro de Relaciones Exteriores, ministro de la Defensa y vicepresidente) en su actual condición de conductor de un programa de TV dijo que la Constitución de 1999 y, específicamente el capítulo dedicado a la protección de derechos humanos, fue redactado "con mentalidad de oposición y no con mentalidad de gobierno". Esta frase es de un realismo pasmoso, especialmente viniendo de alguien que en los años sesenta y setenta 
se dedicó a la defensa de los derechos humanos de los guerrilleros, estudiantes y demás perseguidos políticos de izquierda. Y en efecto, así fue.

En esta materia, la Constitución del 99 es realmente innovadora. Redactado con la participación activa y entusiasta de todas las organizaciones de defensa de los derechos humanos, ese capítulo de la Constitución ata las manos del gobierno, reduciendo al menos formalmente el margen para la arbitrariedad y la represión. En particular, en materia de estados de excepción la Constitución es extraordinariamente progresista. En esta materia, la legislación venezolana estaba en mora. Reiteradas y prolongadas suspensiones de garantías en los años sesenta, destinadas a facilitar la represión de los alzamientos militares y de la guerrilla, y más aún luego de la matanza del 27 y 28 de febrero de 1989 que condujo incluso a una condena e imposición de la obligación de resarcimiento por parte de la Corte Interamericana de Derechos Humanos, eran evidencias suficientes de las imperfecciones en esta materia del marco constitucional establecido en 1961. En contraste, la de 1999 establece expresamente la prohibición de la incomunicación y tortura de los detenidos, garantiza el debido proceso y el derecho a la información, además de otros derechos humanos intangibles.

Chávez también ha propuesto ampliar otros derechos sociales y políticas. En su propuesta de reforma estableció, por ejemplo, la creación de una "Ley Especial para la Creación del Fondo de Estabilidad Social para Trabajadores y Trabajadoras por Cuenta Propia". No obstante, este derecho está ya previsto en la Constitución del 99, aunque de un modo menos preciso. En su artículo 87, la Constitución dice que "La ley adoptará medidas tendentes a garantizar el ejercicio de los derechos laborables de los trabajadores y trabajadoras no dependientes". En todo caso, no hacía falta la reforma de la Constitución para legislar en esta materia. Algo similar ocurre en relación a la jornada laboral. La propuesta de Chávez fue reducir el número de horas de 8 diarias o 44 semanales a 6 diarias o 36 semanales. La constitución del 99 establece que legislación propenderá a la reducción progresiva de la jornada laboral, pero no precisa a cuántas horas. En este asunto el legislador ha estado en mora. El presidente podría aún solventar este retraso haciendo uso de sus poderes legislativos especiales y sin que sea necesario un cambio constitucional.

En cuanto a los derechos políticos, la propuesta introdujo dos innovaciones dignas de ser mencionadas. La Constitución de 1999, que fue redactada en un contexto de profundo rechazo a los partidos políticos, prohíbe absolutamente la financiación pública de los partidos y campañas, la cual se había establecido por ley en 1973 y ampliado en la reforma de ley del sufragio de 1997. El cambio constitucional propuesto por Chávez habría permitido aprobar eventualmente una ley para financiar las actividades electorales con dinero público y para controlar el financiamiento privado. No obstante, los derechos políticos también hubiesen quedado sensiblemente modificados por la propuesta de cambio. Aunque el texto seguía reconociendo el derecho de los ciudadanos a participar en elección de cargos públicos, el referendo y las iniciativas de legislativa y constituyente, también limitaba el uso de estos medios de participación a "la construcción del socialismo" (artículo 70). Es decir, que quien desee participar en política con otros fines distintos a la construcción del socialismo, quedaría al margen de la constitución. En una palabra, esta norma contenida en la propuesta de cambio acaba de suyo con el pluralismo político. 


\section{EL CONTEXTO ECONÓMICO: MÁS BONANZA, MENOS LIBERTAD ECONÓMICA Y MÁS INFLACIÓN}

Venezuela sigue siendo beneficiada por el creciente precio del petróleo. Al cierre del año, la caída de las reservas petroleras de Estados Unidos, el constante crecimiento de la demanda en China y las tensiones políticas en Asia y Medio Oriente han llevado los precios del petróleo venezolanos a rondar los 85 dólares. Aunque nunca es fácil predecir el comportamiento del mercado petrolero y a pesar de que la economía norteamericana no ha dado todavía señales claves de recuperación, el escenario más probable para el año próximo es el de continuación de la bonanza petrolera.

No obstante, escasez e inflación siguen siendo los dos problemas fundamentales de la economía. La política impositiva y los controles de precios, del tipo de cambio y del mercado laboral, combinadas con una política expansiva del gasto público e incesantes amenazas a la propiedad privada industrial y agrícola se han traducido en escasez de los bienes más elementales de consumo (leche, azúcar, papel de todo tipo, harinas, aceites, huevos, carnes y medicamentos) han creado oportunidades para el mercado negro de divisas y de bienes escasos, así como la inflación más alta de América Latina.

Según un reciente boletín emitido por el Banco Central de Venezuela, la inflación anualizada del 2007 cerró en 22,5\%. Esta cifra excedió con creces la observada para el periodo del $2006(17 \%)$ y la meta inflacionaria del 12\% fijada por gobierno y el ente emisor. Aunque los primeros meses del años (especialmente de marzo a septiembre) la inflación parecía estar cediendo al alcanzar cifras inferiores al 2\% mensual, en el último trimestre se aceleró apreciablemente alcanzando un pico de 4,4\% en noviembre. Al cierre de enero del 2008 se espera una inflación superior al 5\%.

Tabla 3: Variaciones Interanuales de Índice de Precios al Consumidor.

Área Metropolitana de Caracas

\begin{tabular}{|c|c|c|c|c|c|c|c|c|c|c|c|c|c|c|}
\hline \multirow{2}{*}{ Período } & \multirow{2}{*}{ IPC } & \multicolumn{13}{|c|}{ Rubros } \\
\hline & & 1 & 2 & 3 & 4 & 5 & 6 & 7 & 8 & 9 & 10 & 11 & 12 & 13 \\
\hline $\begin{array}{l}\text { Nov.07/ } \\
\text { Dic.06 }\end{array}$ & 18,6 & 25,1 & 53,9 & 17,6 & 5,3 & 1,8 & 20,0 & 26,8 & 13,9 & $(5,8)$ & 13,2 & 7,3 & 34,3 & 22,2 \\
\hline $\begin{array}{l}\text { Nov.07/ } \\
\text { Nov.06 }\end{array}$ & 20,7 & 29,3 & 57,1 & 19,5 & 5,5 & 2,0 & 21,3 & 27,5 & 16,2 & $(5,8)$ & 16,2 & 7,3 & 37,8 & 23,5 \\
\hline $\begin{array}{l}\text { Nov.06/ } \\
\text { Nov.05 }\end{array}$ & 15,8 & 23,4 & 18,2 & 8,7 & 6,6 & 2,8 & 17,9 & 12,9 & 14,0 & 7,2 & 10,9 & 16,4 & 24,2 & 12,6 \\
\hline $\begin{array}{l}\text { Prom. Nov- } \\
\text { Ene. } 07\end{array}$ & 18,3 & 26,4 & 30,3 & 13,9 & 6,7 & 2,2 & 21,9 & 22,7 & 13,9 & 0,0 & 15,8 & 12,4 & 31,0 & 18,1 \\
\hline
\end{tabular}

Fuente: Banco Central de Venezuela.

Notas: IPC: Índice de Precios al Consumidor; 1: Alimentos y bebidas no alcohólicas; 2: Bebidas alcohólicas y tabaco; 3: Vestido y calzado; 4: Alquiler de viviendas; 5 : Servicios de vivienda, excepto teléfono; 6: Equipamiento del hogar; 7: Salud; 8: Transporte; 9: Comunicaciones; 10: Esparcimiento y cultura; 11: Servicios de educación; 12: Restaurantes y hoteles; 13: Bienes y servicios diversos. 
La desaceleración de la inflación a mitad de año tuvo que ver en buena medida con la decisión del gobierno de reducir el porcentaje del impuesto al valor agregado (IVA). No obstante, a finales de año el gobierno tomó tres decisiones que pueden haber influido en el incremento de precios. Tales fueron la imposición de una carga de 1,5\% a las transacciones financieras, el incremento de los impuestos a las bebidas alcohólicas y cigarrillos y la liberación de los precios de algunos productos para intentar paliar (sin éxito por el momento) su escasez. A esto se suma el incremento de los productos agrícolas pese al férreo control de precios impuesto por el Ejecutivo.

En medio de este ambiente inflacionario, el Ministerio de Finanzas y el Banco Central de Venezuela han implementado una reconversión monetaria. Las autoridades financieras han creado una nueva moneda, denominada informalmente "bolívar fuerte", la que equivale a 1.000 bolívares tradicionales. El efecto de esta medida en largo plazo está por verse, pero hay razones para pensar que, si no se controla la inflación, la nueva moneda carecerá de la estabilidad buscada. En todo caso, en el corto plazo, la medida contribuirá a la elevación de precios por el redondeo de las fracciones.

El control cambiario y la negativa del gobierno a ajustar el precio del bolívar han llevado a una situación sin precedentes en la economía venezolana. El precio oficial del dólar sigue siendo 2,15 bolívares fuertes. Hasta hace pocas semanas, en el mercado paralelo se cotizaba el dólar varias veces por encima de este valor. No obstante, ya no es posible conocer legalmente el precio de mercado de la divisa norteamericana. Desde la primera semana de enero del 2008 ha entrado en vigencia una ley aprobada por la AN que prohíbe y convierte en delito la difusión de información referida al mercado paralelo del dólar. La violación de esta norma acarrea una multa de cerca de 38 millones de bolívares (38 mil bolívares fuertes) lo que equivale a casi 18 mil dólares.

En cuanto al problema de la escasez, que se tornado agudo en las primeras semanas de diciembre, el gobierno ha accedido a aumentar los precios de algunos rubros alimenticios y liberar ciertos controles, pero en ningún caso ha renunciado a la política general de controles ni mucho menos a las amenazas contra los productores. El presidente, al tiempo que anunció recientemente la elevación de precios de la leche, impuso un ultimátum a los productores de lácteos anunciando que procedería a la expropiación de las haciendas que no cumplieran con las nuevas regulaciones e imposiciones.

\section{EL CONTEXTO INTERNACIONAL: DE BACHE EN BACHE}

El año 2007 fue muy adverso para la política exterior de Venezuela. Una serie de acontecimientos marcaron el fracaso de algunas iniciativas gubernamentales, así como una creciente tensión entre Venezuela, varios de sus socios tradicionales y también algunos de sus nuevos aliados.

La entrada de Venezuela al MERCOSUR se ha visto demorada, pese a las ventajas económicas que tal entrada podría tener para países como Brasil y para la propia Venezuela, debido en buena medida a la retórica encendida del presidente Chávez que no ha economizado 
insultos para referirse al Parlamento del Brasil y de Paraguay, así como también al de Chile. La tensión con estos tres países fue desatada por la ira del presidente venezolano cuando los legislativos de estos tres países expresaron su preocupación por la calidad de la democracia venezolana. El efecto práctico de las polémicas reacciones del presidente de Venezuela ha sido la posposición del ingreso de Venezuela al MERCOSUR por lo menos hasta el 2008.

Por otro lado, al ya invariable conflicto retórico entre el gobierno de Chávez y Estados Unidos se sumó el escándalo provocado por el decomiso en Argentina de una valija con cerca de 800 mil dólares en efectivo, lo cual no sólo puede haber constituido un delito de contrabando en ese país, sino que además es un presunto delito cambiario en Venezuela, de donde es un delito castigado con cárcel de 2 a 6 años el vender o comprar 20 mil o más dólares sin declarar la transacción ante las autoridades. Hasta donde se sabe, el portador de la valija no declaró la transacción que le permitió extraer de Venezuela el monto señalado y trasladarlo a Argentina a bordo de un jet privado en que viajaban funcionarios de las empresas petroleras estatales de Venezuela y Argentina. El escándalo escaló a finales de año con la detención en Miami de varios ciudadano venezolanos y uno de nacionalidad uruguaya, acusados por el FBI de ser agentes del gobierno venezolano que al parecer presionaban al venezolano-americano portador de la valija para que cambiara la versión acerca del origen y destino del dinero en cuestión. Desde el decomiso del mencionado dinero, el gobierno venezolano acusó a los Estados Unidos de urdir una maniobra para enlodar el buen nombre de Venezuela y de su presidente. Esta acusación recrudeció al final del año, al informarse que los dineros decomisados podrían haber sido destinados al financiamiento de la campaña electoral de la actual presidenta de Argentina.

Pero el escándalo de la valija no fue el único incidente internacional que afectó a Venezuela. Un segundo y no menos importante impasse tuvo lugar en Chile, durante la Cumbre Iberoamericana, donde el presidente Chávez protagonizó una discusión con el presidente del gobierno español, José Luis Rodríguez Zapatero, en el cual se involucró abruptamente el Monarca Español, Don Juan Carlos I de Borbón. El incidente ha escalado en lo retórico, pero también en lo económico, pese a los esfuerzos diplomáticos para reducir su impacto. La prensa española ha sistemáticamente atacado al presidente venezolano, llegando incluso (en el caso del diario El Mundo de Madrid) a elegirse a Chávez como el principal enemigo de España en el año 2007. Por su parte, Chávez no sólo llenó de improperios al Rey y al gobierno de España, sino que decidió "congelar" las relaciones con España (aunque sin precisar el alcance real de tal congelamiento). Además ha amenazado con "poner el ojo" sobre las empresas españolas en Venezuela. El primer efecto de esta decisión fue una multimillonaria multa impuesta por Venezuela a la empresa Movistar, filial de la trasnacional española Telefónica.

Un cuarto evento de importantes implicaciones para Venezuela ha sido la creciente tensión entre el gobierno de Chávez y el del colombiano Álvaro Uribe Vélez. La tensión fue originada por la decisión de Uribe de suspender las gestiones que Chávez estuvo realizando con el fin de lograr la liberación de la ex candidata presidencial Ingrid Betancourt, secuestrada por el grupo terrorista colombiano FARC. La presunta intromisión de Chávez en asuntos 
internos de Colombia, más el incumplimiento de la promesa de presentar una fe de vida de Betancourt ofrecida por Chávez, la senadora colombiana Piedad Córdova y las FARC al presidente de Francia, Nicolás Sarkosy, sirvieron de excusas para que Uribe suspendiera unilateralmente las gestiones de Chávez.

Inicialmente, el gobierno venezolano reaccionó diplomáticamente, reconociendo que se trataba de una decisión soberana del gobierno de Colombia, pero a los pocos días Chávez transformo el evento en una confrontación con Uribe. Al igual que en el caso de España, decidió "congelar" las relaciones binacionales y llamó a consulta al embajador en Bogotá. Aunque en este caso el alcance del "congelamiento" tampoco se ha precisado, lo cierto es que las relaciones comerciales entre los dos países (socios tradicionales en esta materia) se han visto afectadas. Un segundo round de este mismo evento se produjo el 31 de diciembre del 2007, cuando una vez más las FARC incumplieron las promesas hechas a Chávez de liberar rehenes como gesto humanitario. Pese a este nuevo fracaso, Chávez insiste en intentar la liberación de los cautivos y promete realizar "operaciones clandestinas" para lograrlo. En el tercer round, las FARC finalmente le entregaron dos rehenes a Chávez, pero dos eventos posteriores han opacado el triunfo inicial que ha podido capitalizar el presidente venezolano por esta liberación. En primer lugar, el presidente pidió a la comunidad internacional que se retirase la calificación de terrorista a las guerrillas colombianas. Hasta ahora, la respuesta de los demás países de Europa y América ha sido negativa. En segundo lugar, Chávez ha escalado a un nivel sin precedentes sus ataques verbales al presidente Uribe de Colombia al cual ha acusado incluso de gánster.

Las tensiones entre Colombia y Venezuela no habían estado tan tensas desde el incidente de la incursión la corbeta "Caldas" de la Armada colombiana en aguas venezolanas el 19 de agosto de 1987. El gobierno venezolano, con la excusa de impedir el contrabando de extracción hacia Colombia, ha desplazado efectivos militares a la frontera. El gobierno de Colombia, por ahora, ha respondido a los ataques con cautela y discreción. No obstante, expertos de ambos países coinciden en señalar que, de continuar la escala, podría llegarse a un enfrentamiento militar.

Finalmente, el verbo de Chávez ha creado dificultades para su política exterior incluso en el caso de Bolivia, su mejor aliado en Suramérica. En el marco de las tensiones que vivió este país en el 2007 como consecuencia del proceso constituyente, Chávez ha amenazado reiteradamente a los opositores de Evo Morales y al "imperialismo" con convertir a Bolivia en el "Vietnam de las ametralladoras" si Morales es depuesto. La vehemencia de sus últimas declaraciones al respecto fue tal (y contrastaron tanto con los llamados del presidente de Bolivia al diálogo) que dirigentes del partido de gobierno en Bolivia (el Movimiento al Socialismo) exigieron moderación por parte del presidente venezolano.

En suma, el balance de la política exterior de Venezuela en el año 2007 es precario. Fue un año de extremo protagonismo de Chávez, pero de pocos logros concretos y de muchos conflictos con aliados tradicionales y nuevos socios. Los principales aciertos tuvieron que ver con la eficacia de la diplomacia petrolera, principalmente en el Caribe. Pese al desmejorado rol que, al parecer, Fidel Castro juega en la política cubana hoy en día, y pese a los rumores de que Raúl Castro y Chávez no tienen el mismo nivel de simpatías mutuas 
que el viejo caudillo caribeño y el presidente venezolano, Chávez sigue teniendo el apoyo explícito de Cuba, los isleños le siguen asesorando y brindando apoyo en áreas claves como salud, economía, educación e inteligencia. Sobre la base de la generosa política de subsidio petrolero, Chávez aún cuenta con fuerte apoyo no sólo de Cuba sino que también de otros países petroleros de la cuenca del Caribe.

\section{LA CALIDAD DE LA DEMOCRACIA VENEZOLANA DESPUÉS DEL REFERÉNDUM: ¿LIBERALIZACIÓN O ENDURECIMIENTO?}

Pese a la polarización existente, una serie de hechos han contribuido a reafirmar el método democrático en Venezuela. Tres hechos son dignos de destacar:

1. Pese al radicalismo de las declaraciones de Chávez en relación al triunfo de la oposición, el gobierno reconoció su derrota y, por tanto, se mantiene dentro de los márgenes de la legalidad y del respeto a los resultados electorales. Hasta la madrugada del 3 de diciembre, y pese a que el gobierno había declarado que reconocería el triunfo de la oposición, sectores de la misma oposición temían que el gobierno no lo haría. Más aún, pese a que Chávez mismo despejó este temor una vez que el CNE anunciara los resultados, en su exposición dijo que había pasado un cierto tiempo pensando y considerando la mejor acción a seguir antes de reconocer su derrota. Pocas horas después, la televisión privada dio a conocer una grabación de una transmisión por radio del alcalde de Caracas, Freddy Bernal, en la que, supuestamente por órdenes de Chávez, ordenaba que las "unidades civiles" y de "motorizados" debían estar "acuarteladas" a fin de dar respuesta a una eventual "toma" de la Plaza Bolívar por parte de líderes de la oposición y sus seguidores, la cual es considerada por Chávez y sus seguidores como "territorio liberado". El alcalde reconoció que la comunicación en cuestión era verdadera, pero añadió que había sido citada fuera de contexto. Más aún, algunos medios de comunicación críticos del gobierno han insistido en que en la reacción de Chávez tuvo mucho que ver la decisión de la mayoría de los generales de alertar al gobierno de los riesgos de violencia y los costos de reprimir en caso de que los resultados no fuesen reconocidos. El gobierno ha negado haber recibido presión de la fuerza armada. Sea como fuere, el hecho de que el gobierno haya reconocido la victoria opositora, pese al margen tan estrecho, es una ganancia para el juego democrático.

2. No sólo el gobierno subió sus puntos democráticos. También lo hizo la oposición. Por otra parte, uno de los resultados más importantes de este proceso ha sido el surgimiento de una oposición democrática que no sólo derrotó al gobierno, sino que se separó y aisló al radicalismo antichavista que había dominado la escena hasta meses antes de la elección. Desde el 2006 y más aún a partir de este referéndum han surgido partidos de oposición de izquierda democrática y social-demócrata que han contribuido a reducir la influencia de la derecha y el radicalismo violento en el electorado.

3. Los moderados de ambos lados han tendido puentes después del referéndum. Un ejemplo elocuente de esto fue la entrevista televisada entre el ex vicepresidente Rangel y 
el alcalde opositor y líder de UNT, Leopoldo López, en el programa de TV que conduce el primero. El tono y contenido del programa fue de necesidad de acuerdo sobre puntos concretos de política pública (incluyendo la inseguridad personal y los problemas de abastecimiento de bienes de consumo). No obstante, el punto clave es que el presidente Chávez adopte una postura conciliadora, lo cual parece actualmente improbable.

No obstante, el método democrático aún vigente en el país no asegura una democracia de calidad. Pese al respeto del juego democrático, la oposición y el gobierno siguen jugando un juego dilemático del tipo cambio de régimen-competencia electoral (Mainwaring and Scully 2003). De un lado, el gobierno se propone un cambio radical del régimen económico y político. Ya que falló la estrategia de reforma constitucional, el cambio lo irá imponiendo por la vía legislativa y mediante decisiones administrativas. Sin embargo, todo indica que el gobierno seguirá intentado legitimarse por medios electorales. Chávez ha anunciado, por ejemplo, que el 2009 promoverá un referéndum revocatorio de su propio mandato que, curiosamente, será también un referéndum aprobatorio de su propuesta ya derrotada de reelección indefinida.

El juego democrático implica mantener ciertas libertades y derechos cívicos tales como la libertad de expresión. No obstante, los periodistas siguen siendo acosados y agredidos por los seguidores del gobierno. Sobre la única televisora privada en señal libre no plegada al gobierno (GLOBOVISÓN) pesa una amenaza de sanción y cierre, pese a que es un pequeño canal de noticias que transmite principalmente vía UHF y sin alcance nacional.

Pero mantener las libertades, aun las pocas que quedan, genera un dilema para el gobierno. Hacer la revolución en democracia requiere la tolerancia de la oposición, pero no tanta tolerancia como para poner en riesgo la revolución misma. El dilema del gobierno es, en suma, determinar a qué ritmo hacer los cambios para reducir la resistencia opositora y cómo vencer a la oposición usando el mínimo posible de la violencia del Estado y de la llamada "violencia popular".

Del otro lado, la oposición quiere detener y deslegitimar al progresivo avance de la llamada "revolución bolivariana", al tiempo que tiene incentivos para participar en elecciones. Por ello, al tiempo que denuncia la falta de transparencia y equidad en la competencia electoral, participa en las elecciones a fin de ganar cargos y legitimidad (autoridad moral). El dilema de la oposición es que al tiempo que participa en elecciones para acumular el poder de demorar, frenar o revertir el proceso de cambio de régimen, con su participación termina legitimando al gobierno y al sistema político que desearía cambiar.

En la actual coyuntura, la propuesta de transición al socialismo introducida por Chávez ha alimentado la polarización política, ha provocado la reacción de diversos sectores y ha generado reacomodos de las coaliciones opositoras y de gobierno. Es cierto que hay una gran volatilidad e incertidumbre política. Los distintos actores políticos cambian de posición y de estrategia de un día para otro. No obstante, hasta ahora la lista de actores se compone de dos, por el lado del gobierno, y tres por el lado de la oposición.

Por el lado del gobierno, existe un sector moderado de los electores, que apoya a Chávez aunque critica el desempeño gubernamental en algunas áreas (principalmente, 
seguridad personal y abastecimiento alimentario). Por el otro, un sector más radical y más incondicionalmente partidario de Chávez, que se vincula al líder por una mezcla de mecanismos utilitarios y afectivos. Mientras el primer grupo puede ser influido por alcaldes y gobernadores chavistas, algunos de los cuales se han manifestado a favor del cambio de Constitución, mientras que otros han mantenido silencio, el segundo grupo sólo conecta con Chávez, principalmente a través de sus discursos y programas de TV.

Esta división de la base electoral de Chávez se expresó claramente en los resultados del referéndum del 2 de diciembre del 2007. La propuesta de Chávez obtuvo cerca de tres millones de votos menos de los que obtuvo en diciembre del 2006. La estrategia plebiscitaria que Chávez siempre ha adoptado en todas las elecciones realizadas desde 1999 no funcionó esta vez. La propuesta perdió en todos los estados más grandes del país, en casi todas las capitales de los estados y en las ciudades más pobladas y en muchos de los barrios populares donde hasta el año 2006 el liderazgo de Chávez parecía incuestionable. Todo indica que un sector importante de los tradicionales votantes por Chávez se abstuvo de votar o votó en contra de la propuesta de reforma.

A su vez, en términos de partidos y de liderazgos políticos, la alianza que apoya a Chávez aparece fracturada. Del lado de la propuesta de cambio socialista radical están los grupos que apoyan al presidente en la AN: el todavía no formalmente constituido PSUV, que sustituye al MVR y sus aliados más importantes, el Partido Patria para Todos y el Partido Comunista de Venezuela. Estos dos grupos que han sido sistemáticamente criticados por Chávez por no sumarse al partido unificado de la revolución, se mantienen leales al presidente, a su gobierno y al programa de cambio radical. No obstante, el secretario general del PPT ha dado recientemente algunas señales de disposición al diálogo con la oposición democrática.

Descontando esta disidencia, dentro del movimiento de Chávez surgen voces que, en contra del discurso radical del presidente, llaman al diálogo y al encuentro con lo que consideran un nuevo sector democrático de la oposición que, desde su punto de vista, abandonó las prácticas violentas, abstencionistas y "golpistas" adoptadas por otros líderes entre el 2002 y 2005. Sin embargo, quienes así han actuado se han expuesto a ser acusados de traidores e incluso a ser marginados del gobierno.

La pregunta en este momento es si acaso en medio del ambiente electoral que arrancó ya de nuevo y no concluirá hasta octubre del 2008, será posible para cada sector (gobierno y oposición) limar sus diferencias internas y coordinar estrategias para presentar candidaturas en los municipios y estados que maximicen sus oportunidades de éxito. Por el lado del gobierno, Chávez siempre ha jugado el rol de gran elector, resolviendo las pugnas internas de su movimiento mediante el "ungimiento" de candidatos y la confección de las listas a órganos legislativos. Este rol podría seguir siendo jugado por el presidente, especialmente si éste logra imponer la reelección indefinida este año o logra convencer a sus partidarios de que lo hará. De otro modo, surgirán múltiples aspirantes a sustituir a Chávez y, en consecuencia, a influir en la nominación de candidatos a gobernar las regiones y municipios. Ya la lucha de tendencias se ha hecho evidente en el seno de los seguidores de Chávez tras la derrota del 2 de diciembre. Ya son evidentes 
los conflictos entre sectores dirigidos por el gobernador y aparente delfín, el teniente (retirado) Diosdado Cabello, el llamado grupo ultrarradical Tupamaro, el vicepresidente Ejecutivo y ex presidente del CNE, Jorge Rodríguez y la presidenta de la AN, Cilia Flores, el diputado líder de la persecución a los peticionarios del referéndum revocatorio del 2004, Luis Tascón (actualmente bajo sanción del tribunal disciplinario de un partido que aún no existe formalmente: el PSUV) y los líderes de los pequeños partidos de la coalición de gobierno que pujan por no ser absorbidos por el partido dominante en la misma (PPT y PCV). Dos hitos han creado importantes polémicas en el "chavismo:" la formación del partido único y la responsabilidad por la derrota electoral. En año electoral se puede prever que los conflictos aumentarán sin que exista una instancia institucional, distinta del liderazgo personalista de Chávez, que permita dirimir las diferencias de un modo consensual o al menos con bajo costo político.

Para la oposición ha sido igualmente difícil coordinar estrategias conjuntas y presentar candidaturas de unidad en elecciones legislativas y subnacionales. La vez que estuvo más cerca de hacerlo fue en el año 2005 cuando finalmente, a pocas semanas de los comicios, decidieron retirarse de la contienda. En el bloque opositor, además, han surgido nuevos actores con aspiraciones a cargos. En concreto, el partido PODEMOS, que actualmente controla dos gobernaciones y el General Baduel, de quien se dice que aspira a una gobernación, tendrán dificultades para coordinar estrategias con la oposición emergente de izquierda y centro-derecha representada por UNT y MPJ, especialmente si estos partidos pactan con los partidos tradicionales (AD y COPEI).

En medio de esto, no obstante, la confrontación política al parecer seguirá dominada por la lógica de la confrontación radical. El gobierno, como se ha dicho, sigue empeñado en pasar la reforma que fracasó electoralmente usando cualquier otra oportunidad electoral, resquicio legal o sentencias del TSJ e interpretaciones de la Constitución por parte de la Sala Constitucional que permitan legitimar las decisiones del gobierno sin recurrir a nuevas consultas populares. La oposición, que se percibe a sí misma como políticamente efectiva luego del triunfo electoral (el primero realmente importante en nueve años), estará dispuesta a enfrentar los intentos del gobierno haciendo uso de recursos legales y de movilizaciones en las calles. Todo esto en medio de un contexto electoral que generará conflictos no sólo entre opositores y gobernantes, sino también dentro de cada coalición por las dificultades derivadas de la selección de los candidatos y la formación de alianzas.

\section{REFERENCIAS}

Álvarez, A. E., J. C. Fernández, et al. 1999. La institución presidencial venezolana. Caracas: Facultad de Ciencias Jurídicas y Políticas, Universidad Central de Venezuela.

Álvarez Díaz, A. E. 2006. "Social Cleavages, Political Polarization and Democratic Breakdown in Venezuela". Stockholm Review of Latin American Studies 1 (1): 18-28.

Dietrich, H. 2005. Hugo Chávez y el Socialismo del Siglo XXI. Caracas, Venezuela, Instituto Municipal de Publicaciones. Alcaldía de Caracas.

Mainwaring, S. and T. R. Scully. 2003. Party Objetives in Authoritarian Regimes with Elections and Fragile Democracies: A Dual game. In Christian Democracy in Latin America edited by S. Mainwaring and T. R. Scully. Stanford, California, Stanford University Press. 
Mainwaring, S. and M. S. Shugart. 1997. Conclusion: Presidentialism and the Party System. In Presidentialism and Democracy in Latin America. Edited by S. Mainwaring and M. S. Shugart. Cambridge, Cambridge University Press: 394-439.

Roberts, K. M. 2003. Social Polarization and the Populist Resurgence in Venezuela. In Venezuelan Politics in the Chavez Era. Edited by S. Ellner and D. Hellinger. Boulder, CO, Lynne Reinner Publishers: 55-72. 
Apéndice 1: Resultados en la ciudad de Caracas del Referéndum Constitucional del 2007. Datos en porcentajes

\begin{tabular}{|c|c|c|c|c|c|c|c|}
\hline \multirow{2}{*}{ Municipio } & \multirow{2}{*}{$\begin{array}{c}\text { Alcalde } \\
\text { (Filiación Política) }\end{array}$} & \multirow{2}{*}{ Parroquia } & \multirow{2}{*}{$\begin{array}{l}\text { Chávez } \\
2006\end{array}$} & \multicolumn{2}{|c|}{ Bloque A } & \multicolumn{2}{|c|}{ Bloque B } \\
\hline & & & & No & Sí & No & Sí \\
\hline \multirow{23}{*}{ Libertador } & \multirow{23}{*}{$\begin{array}{l}\text { Freddy Bernal } \\
\text { (Gobierno, PSUV) }\end{array}$} & & 62,75 & 52,41 & 47,58 & 52,84 & 47,15 \\
\hline & & 23 de Enero & 75,58 & 39,71 & 60,29 & 40,08 & 59,92 \\
\hline & & Altagracia & 53,70 & 58,74 & 41,26 & 59,08 & 40,92 \\
\hline & & Antímano & 81,79 & 33,19 & 66,81 & 33,74 & 66,26 \\
\hline & & Candelaria & 41,18 & 69,66 & 30,34 & 70,16 & 29,84 \\
\hline & & Caricuao & 62,52 & 54,02 & 45,98 & 54,56 & 45,44 \\
\hline & & Catedral & 71,01 & 38,46 & 61,54 & 39,26 & 60,74 \\
\hline & & Coche & 64,48 & 51,66 & 48,34 & 52,12 & 47,88 \\
\hline & & El Junquito & 64,90 & 51,49 & 48,51 & 51,89 & 48,11 \\
\hline & & El Paraíso & 42,32 & 70,49 & 29,51 & 70,88 & 29,11 \\
\hline & & El Recreo & 39,94 & 70,03 & 29,97 & 70,30 & 29,70 \\
\hline & & El Valle & 69,70 & 46,75 & 53,25 & 47,13 & 52,87 \\
\hline & & La Pastora & 61,90 & 52,16 & 47,84 & 52,58 & 47,42 \\
\hline & & La Vega & 64,75 & 51,08 & 48,92 & 51,60 & 48,40 \\
\hline & & Macarao & 79,95 & 37,58 & 62,42 & 38,31 & 61,69 \\
\hline & & San Agustín & 67,49 & 44,27 & 55,73 & 44,83 & 55,17 \\
\hline & & San Bernardino & 38,06 & 71,52 & 28,48 & 72,01 & 27,99 \\
\hline & & San José & 54,78 & 60,01 & 39,99 & 60,46 & 39,54 \\
\hline & & San Juan & 62,28 & 52,77 & 47,23 & 53,25 & 46,75 \\
\hline & & San Pedro & 32,26 & 76,33 & 23,67 & 76,26 & 23,74 \\
\hline & & Santa Rosalía & 63,42 & 50,69 & 49,31 & 51,17 & 48,83 \\
\hline & & Santa Teresa & 52,20 & 63,74 & 36,26 & 64,13 & 35,87 \\
\hline & & Sucre & 74,25 & 42,57 & 57,43 & 43,07 & 56,93 \\
\hline \multirow{7}{*}{ Sucre } & \multirow{7}{*}{$\begin{array}{l}\text { José V. Rangel } \\
\text { (Gobierno, PSUV) }\end{array}$} & & 53,17 & 61,59 & 38,41 & 62,02 & 37,98 \\
\hline & & Caucaguita & 72,47 & 40,43 & 59,57 & 40,96 & 59,04 \\
\hline & & F. de Mariche & 79,86 & 34,95 & 65,05 & 35,07 & 64,93 \\
\hline & & La Dolorita & 78,40 & 38,49 & 61,51 & 39,28 & 60,72 \\
\hline & & L. Martínez & 26,44 & 81,54 & 18,46 & 81,92 & 18,08 \\
\hline & & Petare & 53,59 & 61,49 & 38,51 & 61,88 & 38,12 \\
\hline & & & 24,25 & 83,36 & 16,64 & 83,53 & 16,47 \\
\hline \multirow{3}{*}{ Baruta } & \multirow{3}{*}{$\begin{array}{l}\text { Henrique Capriles } \\
\text { (Oposición, MPJ) }\end{array}$} & Baruta & 24,16 & 83,3 & 16,7 & 83,47 & 16,53 \\
\hline & & El Cafetal & 10,93 & 92,42 & 7,58 & 92,55 & 7,45 \\
\hline & & Las Minas & 42,09 & 70,14 & 29,86 & 70,4 & 29,6 \\
\hline Chacao & $\begin{array}{l}\text { Lepoldo López } \\
\text { (Oposición, UNT) }\end{array}$ & Chacao & 23,37 & 83,68 & 16,32 & 16,08 & 83,92 \\
\hline El Hatillo & $\begin{array}{l}\text { Alfredo Catalán } \\
\text { (Oposición, Proyecto } \\
\text { Venezuela) }\end{array}$ & El Hatillo & 20,36 & 86,99 & 13,01 & 87,23 & 12,77 \\
\hline
\end{tabular}

Nota: A = Clase Alta; B = Clase Media Alta; C= Clase Media Baja; D = Clase Baja.

Fuente: Elaboración propia con base a datos del CNE. 
Apéndice 2: Resultados del Referéndum Constitucional del 2 de diciembre 2007. Porcentajes Agrupados por Estados

\begin{tabular}{|c|c|c|c|c|c|}
\hline \multirow{2}{*}{ Entidades Federales } & \multicolumn{2}{|c|}{ Bloque A } & \multicolumn{2}{|c|}{ Bloque B } & \multirow{2}{*}{$\begin{array}{l}\text { Porcentaje de } \\
\text { Población }\end{array}$} \\
\hline & No & Sí & No & Sí & \\
\hline Zulia & $56,94 \%$ & $43,05 \%$ & $57,25 \%$ & $42,74 \%$ & $13,17 \%$ \\
\hline Miranda & $56,21 \%$ & $43,78 \%$ & $56,65 \%$ & $43,30 \%$ & $10,40 \%$ \\
\hline Carabobo & $52,82 \%$ & $47,17 \%$ & $53,12 \%$ & $46,87 \%$ & $8,10 \%$ \\
\hline Distrito Capital & $52,41 \%$ & $47,58 \%$ & $52,84 \%$ & $47,15 \%$ & $7,59 \%$ \\
\hline Lara & $51,02 \%$ & $48,97 \%$ & $51,50 \%$ & $48,50 \%$ & $6,53 \%$ \\
\hline Aragua & $47,07 \%$ & $52,92 \%$ & $47,42 \%$ & $52,57 \%$ & $6,06 \%$ \\
\hline Bolívar & $47,29 \%$ & $52,70 \%$ & $47,59 \%$ & $52,40 \%$ & $5,58 \%$ \\
\hline Anzoátegui & $54,39 \%$ & $45,60 \%$ & $54,65 \%$ & $45,34 \%$ & $5,38 \%$ \\
\hline Táchira & $57,31 \%$ & $42,68 \%$ & $57,50 \%$ & $42,49 \%$ & $4,28 \%$ \\
\hline Sucre & $48,92 \%$ & $51,07 \%$ & $49,11 \%$ & $50,88 \%$ & $3,34 \%$ \\
\hline Falcón & $49,87 \%$ & $50,12 \%$ & $50,23 \%$ & $49,76 \%$ & $3,28 \%$ \\
\hline Portuguesa & $36,92 \%$ & $63,08 \%$ & $37,31 \%$ & $62,68 \%$ & $3,18 \%$ \\
\hline Monagas & $42,12 \%$ & $57,87 \%$ & $42,35 \%$ & $57,64 \%$ & $3,11 \%$ \\
\hline Mérida & $54,71 \%$ & $45,28 \%$ & $54,83 \%$ & $45,16 \%$ & $3,07 \%$ \\
\hline Barinas & $44,07 \%$ & $55,92 \%$ & $44,31 \%$ & $55,68 \%$ & $2,75 \%$ \\
\hline Guárico & $41,64 \%$ & $58,35 \%$ & $41,87 \%$ & $58,12 \%$ & $2,71 \%$ \\
\hline Trujillo & $37,83 \%$ & $62,16 \%$ & $38,01 \%$ & $61,98 \%$ & $2,59 \%$ \\
\hline Yaracuy & $47,56 \%$ & $52,43 \%$ & $47,92 \%$ & $52,07 \%$ & $2,17 \%$ \\
\hline Apure & $38,83 \%$ & $61,16 \%$ & $39,00 \%$ & $60,99 \%$ & $1,72 \%$ \\
\hline Nueva Esparta & $56,09 \%$ & $43,90 \%$ & $56,25 \%$ & $43,74 \%$ & $1,59 \%$ \\
\hline Vargas & $43,79 \%$ & $56,21 \%$ & $44,34 \%$ & $55,65 \%$ & $1,21 \%$ \\
\hline Cojedes & $39,12 \%$ & $60,87 \%$ & $39,35 \%$ & $60,64 \%$ & $1,09 \%$ \\
\hline Delta Amacuro & $39,03 \%$ & $60,96 \%$ & $39,28 \%$ & $60,71 \%$ & $0,56 \%$ \\
\hline Amazonas & $34,23 \%$ & $65,76 \%$ & $42,05 \%$ & $57,94 \%$ & $0,52 \%$ \\
\hline
\end{tabular}

Fuente: Consejo Nacional Electoral.

Ángel E. Álvarez es Politólogo. Director del Instituto de Estudios Políticos de la Universidad Central de Venezuela. Profesor de Postgrado de Procesos y Sistemas Electorales de la misma universidad. Conferencista, articulista de prensa y autor de libros sobre política y elecciones venezolanas y latinoamericanas.

(E-mail: aalvarez@nd.edu) 